\title{
Role of Allama Iqbal Open University in Human Resource Development
}

\author{
Madiha Islam ${ }^{1}$, Nazar Abbas Nazar ${ }^{2}$, Mian Baqar Hussain Qureshi ${ }^{3}$, \\ Nuzhat Kalsoom Shahzadi ${ }^{4}$ \\ ${ }^{I}$ MS Leading to PhD, Faculty of Education, Allama Iqbal Open University, Islamabad, PAKISTAN \\ ${ }^{2} \mathrm{PhD}$ Scholar, Faculty of Education, Allama Iqbal Open University, Islamabad, PAKISTAN \\ ${ }^{3}$ PhD Scholar, Allama Iqbal Open University, Islamabad, Pakistan \\ ${ }^{4}$ PhD Scholar, Allama Iqbal Open University, Islamabad, Pakistan
}

\begin{abstract}
Doubtless to say, that effective management of human resources is one of the few levers that managers have at their disposal to accomplish their organizational strategic objectives. Hence, HRM is a key factor for the success of distance organization. AIOU has significant role in the training of skilled human resources to mange economy, to facilitate generation specially females, advancement of knowledge in all fields and to minimise unemployment rate. It's approach is best suited to reach the rural and far-flung areas of Pakistan. Purposes of the study were: (i)to identify the challenges of human resource management(ii) (ii) to highlight the role of AIOU in addressing the challenges for national development(iii) to suggest the measures for the development of human resources. A sample of 23 faculty members was taken conveniently. A questionnaire was used as a research tool for the collection of data. Collected data were analyzed through SPSS XIV by running frequencies, mean score.

Main findings of the study revealed that AIOU finds positive ways to cope with sustainability challenges as it meets the needs of his clients.AIOU is the best for learning with earning, hence it has made a revolution in Pakistani economy. In Pakistan, AIOU has fulfilled shortage of trained and skilled manpower. In this technological era, AIOU is trying to meeting all requirements of his customers. Through professional training of teachers as well as tutors, AIOU is playing role in national development. Maximum deployment of computers and internet may be ensured in their study centers.
\end{abstract}

Key words: Human resource development, National development, Challenges. AIOU

With technologies evolving every day, human resources professionals are realizing that the fast-paced, ever-changing digital world impacts their jobs and workplaces — not only today, but in the future.

Bersin \& Associates, a global research and consulting firm focused on learning, talent and human resources strategies, recently published a report on the Top Best Practices for the High-Impact HR Organizations. The report noted that overall budgets, organizational structure and department size have less impact on business performance than the skills of HR professionals themselves. The research also outlined the key competencies driving results today - familiarity with integrated talent management, understanding of workforce planning and comfort with social networking and HR technology.

HRM is that it is the process of managing people in organizations in a structured and thorough manner. This covers the fields of staffing (hiring people), retention of people, pay and perks setting and management, performance management, change management and taking care of exits from the company to round off the activities. This is the traditional definition of HRM which leads some experts to define it as a modern version of the Personnel Management function that was used earlier. The second definition of HRM encompasses the management of people in organizations from a macro perspective i.e. managing people in the form of a collective relationship between management and employees. This approach focuses on the objectives and outcomes of the HRM function. What this means is that the HR function in contemporary organizations is concerned with the notions of people enabling, people development and a focus on making the "employment relationship" fulfilling for both the management and employees. These definitions emphasize the difference between Personnel Management as defined in the second paragraph and human resource management as described in the third paragraph. To put it in one sentence, personnel management is essentially "workforce" centered whereas human resource management is "resource" centered. The key difference is HRM in recent times is about fulfilling management objectives of providing and deploying people and a greater emphasis on planning, monitoring and control. 


\section{Whatever the definition we use the answer to the question as to "what is HRM?" is that it is all about people in organizations.}

Human Resource (HR) Management: The design of formal systems in an organization to ensure effective and efficient use of human talent to accomplish organizational goals.

According to Barney (1991), resources must meet four criteria to be able to generate sustained competitive advantage: value, rarity, imperfect limitability, and non-substitutability. Whereas financial capital and technology fulfilled these criteria in the past, these resources "are now available to anyone who can buy [it]" (Handy, 1996, p. 180). Consequently, more organizations are finding that "their enduring source of competitive advantage rests within their human capital" (Heil et al., 2000, p. 4) - the "knowledge, experience, skills and energy of their people" (O'Reilly \& Pfeffer, 2000, p. 3). However, Human Capital Theory states that the market value of human potential can only be realized if employees co-operate (Jackson \& Schuler, 1999). However, contemporary employees are motivated by interesting work that provide rewards in the form of "the freedom to influence the nature of their jobs and pursue their own lifestyles" and have "a growing expectation that work will provide self-respect, nonmaterial rewards, and substantial opportunities for personal growth" (Shaw \& Barry, 1997, p. 166). While managers "speak of efficiency, productivity and the bottom line; employees tend to talk about growth, satisfaction and contribution" (Kaye, 1999, p. 578). It is thus apparent that motivating people to elicit the co-operation necessary for achieving a competitive advantage is a significant challenge for the healthy organization.

\section{HR and Knowledge Management}

Knowledge management has become a fashionable term in organizations today. We can define knowledge management as the discipline that promotes an integrated approach to identifying, capturing, retrieving, sharing, and evaluating an enterprise's information assets. These information assets may include databases, documents, policies, and procedures as well as uncaptured, tacit expertise and experience resident in individual workers.

There are several roles that can be played by HR in developing knowledge management system.

First, HR should help the organization articulate the purpose of the knowledge management system. Investing in a knowledge management initiative without a clear sense of purpose is like investing in an expensive camera that has far more capabilities than you need to take good pictures of family and friends.

Second, as a knowledge facilitator, HRM must ensure alignment among an organization's mission, statement of ethics, and policies: These should all be directed toward creating an environment of sharing and using knowledge with full understanding of the competitive consequences..

Third, HRM should also create the "ultimate employee experience." That is, by transforming tacit knowledge into explicit knowledge through education, organizations must build employee skills, competencies, and careers, creating "bench strength." This combines the traditional training and development responsibilities of HRM with the new responsibilities of human capital steward: using all of the organization's resources to create strategic capability.

Fourth, HRM must integrate effective knowledge sharing and usage into daily life. That is, knowledge sharing must be expected, recognized, and rewarded. For many individuals and organizations, this reverses the conventional relationship between knowledge and power. Human resource management has the capabilities for creating, measuring, and reinforcing a knowledge-sharing expectation.

Fifth, HRM must relax controls and allow (even encourage) behaviors that, in the clockwork world of industrial efficiency, never would have been tolerated.

Sixth, HRM must take a strategic approach to helping firms manage email, instant messenger, internet surfing, and similar uses of technology. Clearly, the Internet has a role in generating and disseminating knowledge, and therefore is an integral part of knowledge management.. Human resource management can contribute to developing social capital by sensitizing employees to the negative consequences of excessive reliance on electronic media and by creating opportunities for face-to-face contact.

Seventh, HRM must champion the low-tech solutions to knowledge management. Although it should not ignore the high-tech knowledge management tools.

HR Management Competencies and Careers Important HR Competencies: 


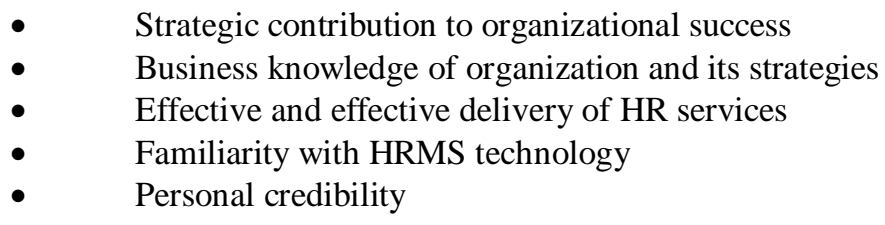

\section{HR Technology}

Human Resource Management System (HRMS)

- $\quad$ An integrated system providing information used by HR management in decision making.

- $\quad$ Purposes (Benefits) of HRMS

- $\quad$ Administrative and operational efficiency in compiling HR data

- Availability of data for effective HR strategic planning

- $\quad$ Uses of HRMS

- $\quad$ Automation of payroll and benefit activities

- $\quad$ EEO/affirmative action tracking

- HR Workflow: increased access to HR information

- $\quad$ Employee self-service reduces HR costs

Human resources are undoubtedly the key resources in an organization, the easiest and the most difficult to manage! The objectives of the HRM span right from the manpower needs assessment to management and retention of the same. To this effect Human resource management is responsible for effective designing and implementation of various policies, procedures and programs. It is all developing and managing knowledge, skills, creativity, aptitude and talent and using them optimally. Human Resource Management is not just limited to manage and optimally exploit human intellect. It also focuses on managing physical and emotional capital of employees. Considering the intricacies involved, the scope of HRM is widening with every passing day. It covers but is not limited to HR planning, hiring (recruitment and selection), training and development, payroll management, rewards and recognitions, Industrial relations, grievance handling, legal procedures etc. In other words, we can say that it's about developing managing harmonious relationships at workplace and striking a balance between organizational goals and individual goals.

\section{HR Management Challenges}

- Workforce Availability and Quality Concerns

- Inadequate supply of workers with needed skills for "knowledge jobs"

- $\quad 80 \%$ of manufacturing jobs report shortage of qualified workers

- $\quad$ Education of workers in basic skills

- $\quad$ Not enough specific skills, not enough technology skills

- Growth in Contingent Workforce

- $\quad$ Represents $20 \%$ of the workforce

- Increases in temporary workers, independent contractors, leased employees, and part-timers caused by:

- $\quad$ Need for flexibility in staffing levels

- Increased difficulty in firing regular employees.

- $\quad$ Reduced legal liability from contract employees

- $\quad$ Boeing Strategy- manage employment cycles in suppliers and partners

- Workforce Demographics and Diversity

- Increasing Racial/Ethnic Diversity

- $\quad$ From the Melting Pot to the Salad Bowl

- More Women in the Workforce

- $\quad$ Single-parent households

- Dual-career couples

- Domestic partners

- Working mothers and family/childcare

- $\quad$ Significantly Aging Workforce

- $\quad$ Age discrimination

- Organizational Cost Pressures and Restructuring

- $\quad$ Mergers and Acquisitions

- "Right-sizing" - eliminating of layers of management, closing facilities, merging with other organizations, and outplacing workers

- Intended results are flatter organizations, increases in productivity, quality, service and lower costs.

- Costs are "survivor mentality", loss of employee loyalty, and turnover of valuable employees. 
- $\quad$ must work toward ensuring cultural compatibility in mergers

\section{HR manages HR Management Roles}

- Administrative Role

- Clerical and administrative support operations (e.g., payroll and benefits work)

- Technology is transforming how HR services are delivered.

- $\quad$ Outsourcing HR services to reduce HR staffing costs

- Operational and Employee Advocate Role

- "Champion" for employee concerns

- Employee crisis management

- Responding to employee complaints

\section{What are challenges faced by human resource management?}

Two types of challenges are faced by HRM today.

\section{*THE CHANGING ENVIRONMENT}

1. Work force diversity

2. Economical \& Technological changes

3. Globalization

4. Organization Restructuring

5. Changing nature of work

*CHANGING ROLE OF THE HR MANAGER
1. Flatter organization
2. Employee empowerment
3. Team work
4. Ethical management

Human Resource Management used to be considered as other conventional administrative jobs. But over a period of time, it has evolved as a strategic function to improve working environment, plan out human resources needs and strike a balance between the organization and employers in order to increase organizational productivity and meet organizational goals. Not to exaggerate but in today's highly competitive world it has gradually become one of the most important functions of an organization. It is really a huge challenge to understand the psychology of workforce, retain the best talents of the industry, motivate them to perform better and handle diversity while maintaining unity simultaneously, especially in countries like India, where it is still evolving. Globalization has resulted in many positive developments but it has left many concerns for HR managers.

\section{Role Of Allama Iqbal Open Universty (AIOU)}

In 1974, Govt. of Pakistan, relizing the need and time ,finalized to establish Open university. The AIOU $<$ distance -learning institution, has been striving to supplement the endeavors of the government for the creation of knowledge -based society in Pakistan, which will go a long way in ensuring a bright and prosperous future for all.( Vice Chancellor 's report,2009-10).AIOU use the following packages to access its clients. Online teaching, Satellite Transmission, Non-broadcast media, Face to face teaching, workshops, course assignments .

AIOU is addressing the challenges of Human resource management very positively for the national development.

- Quantity education,

- Female education,

- Learning with earning,

- Higher education,

- Unemployment,

- Technological innovations

- Professional development of tutors and teachers

- Economical Pressure

\section{OBJECTIVES OF THE STUDY:}


Objectives of the study were:

- $\quad$ To identify the challenges of human resource management

- To highlight the role of AIOU in addressing the challenges for national development

- $\quad$ To suggest the measures for the development of human resources.

Sampling

\section{RESEARCH METHODOLOGY}

It was a descriptive study therefore, survey was considered appropriate for this study. Faculty of education, AIOU, Islamabad was taken as a sample.

\section{Instruments and their Development}

In this survey, a questionnaire on five points (Likert Scale) was used for the collection of data. In the questionnaire items towards Quantity education, female education, learning with earning, higher education, unemployment, technological innovations and professional development of tutours and teachers were asked to elicit the valuable opinions of the respective respondents.A questionnaire was developed on five point (likert) to know the opinion of faculty members. The finalized research tool was administered on the respective sample for the collection of data. Collected data was analyzed through percentage and mean score. Responses of 22 out Of 23 respondents were interpreted and presented in percentage.

\section{Data Analysis}

The data collected through questionnaire was analyzed by using mean, percentage and standard deviation formulas through SPSS.

Table1:

\begin{tabular}{|c|c|c|c|c|c|c|c|c|}
\hline S.No. & Statement & $\mathbf{S A}$ & $\mathbf{A}$ & UNC & DA & SDA & $\%$ & Mean \\
\hline 1 & $\begin{array}{l}\text { Managing human resources is vital } \\
\text { for the success of any distance } \\
\text { organization. }\end{array}$ & 10 & 10 & 0 & 02 & 0 & 90.9 & 4.27 \\
\hline 2 & $\begin{array}{l}\text { Distance institution relies on } \\
\text { professional academia and skilled } \\
\text { workers. }\end{array}$ & 10 & 08 & 0 & 02 & 02 & 81.8 & 4.0 \\
\hline 3 & $\begin{array}{l}\text { AIOU finds positive ways to cope } \\
\text { with sustainability challenges }\end{array}$ & 09 & 11 & 0 & 03 & 0 & 90.9 & 4.31 \\
\hline 4 & $\begin{array}{l}\text { AIOU provides an easy access to get } \\
\text { female education of rural areas. }\end{array}$ & 10 & 11 & 0 & 01 & 0 & 95.4 & 4.36 \\
\hline 5 & AIOU meets the needs of his clients. & 09 & 11 & 0 & 02 & 0 & 90.9 & 4.22 \\
\hline 6 & $\begin{array}{l}\text { AIOU is fulfilling Global } \\
\text { challenges in terms of score and } \\
\text { quality }\end{array}$ & 10 & 10 & 0 & 02 & 0 & 90.9 & 4.27 \\
\hline 7 & $\begin{array}{l}\text { AIOU is the best for learning with } \\
\text { earning. }\end{array}$ & 11 & 10 & 0 & 01 & 0 & 95.4 & 4.41 \\
\hline 8 & $\begin{array}{l}\text { Distance education has effective } \\
\text { role in providing adult education. }\end{array}$ & 10 & 09 & 0 & 02 & 01 & 86.3 & 4.13 \\
\hline 9 & $\begin{array}{l}\text { Through adult education, AIOU has } \\
\text { made a revolution in Pakistani } \\
\text { economy. }\end{array}$ & 11 & 10 & 0 & 01 & 0 & 95.4 & 4.41 \\
\hline 10 & $\begin{array}{l}\text { Rate of unemployment has deceased } \\
\text { due to distance education. }\end{array}$ & 12 & 09 & 0 & 0 & 01 & 95.4 & 4.41 \\
\hline 11 & $\begin{array}{l}\text { In Pakistan, AIOU has fulfilled } \\
\text { shortage of trained and skilled } \\
\text { manpower. }\end{array}$ & 10 & 09 & 0 & 03 & 0 & 86.3 & 4.18 \\
\hline 12 & $\begin{array}{l}\text { In Pakistan, AIOU has fulfilled } \\
\text { shortage of trained and skilled }\end{array}$ & 09 & 09 & 0 & 02 & 02 & 81.8 & 3.95 \\
\hline
\end{tabular}


Role of Allama Iqbal Open Universty in Human Resorce Development

\begin{tabular}{|c|l|c|c|c|c|c|c|c|}
\hline & \multicolumn{1}{|c|}{ manpower. } & & & & & & & \\
\hline 13 & $\begin{array}{l}\text { AIOU has a significant role in } \\
\text { providing Higher Education. }\end{array}$ & 17 & 04 & 0 & 01 & 0 & 95.4 & 4.68 \\
\hline 14 & $\begin{array}{l}\text { In this technological era, AIOU is } \\
\text { trying to meeting all requirements of } \\
\text { his customers. }\end{array}$ & 10 & 08 & 0 & 03 & 01 & 81.8 & 4.04 \\
\hline 15 & $\begin{array}{l}\text { Through professional training of } \\
\text { teachers as well as tutors, AIOU is } \\
\text { playing role in national } \\
\text { development. }\end{array}$ & 11 & 10 & 0 & 01 & 0 & 95.4 & 4.41 \\
\hline
\end{tabular}

Scale value for this table is SA (Strongly Agree) $=5$, A $($ Agree $)=4$, UNC $($ Uncertain $)=3$, DA $($ Disagree $)=2$ and SDA (Strongly Disagree) $=1$

It is evident from the table that AIOU provides an easy access to get female education of rural areas. AIOU has a significant role in providing Higher Education. Rate of unemployment has decreased due to distance education and. Through professional training of teachers as well as tutors, AIOU is playing role in national development. $95.4 \%$ respondents support these statements Managing human resources is vital for success of any distance organization. $90.9 \%$ of respondent agree this statement. AIOU is fulfilling the global challenges and needs of his client. All the responses are above then $81 \%$.Mean score of all is above 3.95 which shows that managing human resources a great challenge. More than $90 \%$ showed their opinions in favour of A.I.O.U has significant role in providing adult education and decreasing unemployment through adult education by making a revolution in Pakistan economy. Majority of respondents viewed that A.I.O.U is playing a significant role in national development.

\section{CONCLUSIONS}

Doubtless to say, that managing human resources is necessary and essential for the success of any distance organization. Distance institution relies on professional academia and skilled workers. AIOU is very effective for enriching education to enhance female qualification at remount areas. An easy access to ocean of knowledge is provided by AIOU through giving opportunity of intensive and extensive study of subject matter. AIOU finds positive ways to cope with sustainability challenges as it meets the needs of his clients .AIOU is fulfilling Global challenges in terms of score and quality .

AIOU is the best for learning with earning, hence it has made a revolution in Pakistani economy. Distance education has effective role in providing adult education. Rate of unemployment has deceased due to distance education. In Pakistan, AIOU has fulfilled shortage of trained and skilled manpower. In this technological era, AIOU is trying to meeting all requirements of his customers. Through professional training of teachers as well as tutors, AIOU is playing role in national development. Therefore it is recommend that a more holistic approach may be adopted for the development of human resources for more and more productivity and quality output. Maximum deployment of computers and internet may be ensured in their study centers .Therefore, for the easy and cheaper access to Internet technology, a holistic policy may be devised with the collaboration of PTCL. Cheaper and in installments Lap Top computers may be provided to distance learners with the cooperation of various national and multi national companies.

\section{References}

[1] AIOU (2011) Chancellor 's Report (2009-10),Islamabad:Allama Iqbal Open University

[2] Barney, J. (1991). Firm resources and sustained competitive advantage. Journal of Management, 17(1), 99-120.

[3] Bartlett, C.A. \& Ghoshal, S. (1994). Changing the role of top management: beyond strategy to purpose. Harvard Business Review, 72(6), 79-88.

[4] Hall, D.T. (1996). Introduction: long live the career - a relational approach to careers. In D.T. Hall \& Associates (Eds). The career is dead, long live the career, a relational approach to careers (pp. 1-14). San Francisco: Jossey-Bass.

[5] O'Reilly, C.A. \& Pfeffer, J. (2000). Hidden value: how great companies achieve

a. extraordinaryresults with ordinary people. Boston, MA: Harvard

b. Business School Press.

[6] Shaw, W.H. \& Barry, V. (1995). Moral issues in business (6th ed.). Belmont, CA:

[7] Wadsworth. Soliman, F. \& Spooner, K. (2000). Strategies for implementing knowledge management: role of human resources management. Journal of Knowledge Management, 4(4), 337

[8] Ph.D Study Guide (2010) Human Resoure Mangement In Distance Education

a. AIOU,Islambad. 